\title{
The potential of pedicled pericardium
}

\author{
Ming-Sing Si, MD
}

\author{
From the Department of Cardiac Surgery, Section of Pediatric Cardiovascular Surgery, University of Michigan, \\ Ann Arbor, Mich. \\ Disclosures: Author has nothing to disclose with regard to commercial support. \\ Received for publication Sept 18, 2016; accepted for publication Sept 19, 2016; available ahead of print Oct 14, \\ 2016. \\ Address for reprints: Ming-Sing Si, MD, 11-735 C.S. Mott Children's Hospital, SPC 4204, 1540 E Hospital Dr, \\ Ann Arbor, MI 48109-4204 (E-mail: mingsing@umich.edu). \\ J Thorac Cardiovasc Surg 2017;153:e15-6 \\ $0022-5223 / \$ 36.00$ \\ Copyright (C) 2016 by The American Association for Thoracic Surgery \\ http://dx.doi.org/10.1016/j.jtcvs.2016.09.043
}

Intermediate-sized arteries provide important resistance in the circulation and smaller blood vessels (capillaries) function to accomplish mass transfer from the blood to adjacent parenchymal cells; in contrast, the primary function of large-caliber vascular structures such as main and branch pulmonary arteries is to serve as conduits for bulk blood flow. Several common congenital heart defects are characterized by the absence or deficiency of the main pulmonary artery and right ventricular outflow tract, thereby causing the absence or obstruction to pulmonary arterial blood flow. Repair of these congenital heart defects requires reconstruction and uses autologous, allogeneic, xenogenic or synthetic material to serve as a conduit for blood flow from the right ventricle to the lungs.

Needless to say, many of these surgical repairs are not durable, because the reconstructed right ventricular outflow tract and pulmonary artery cannot regenerate and grow, and thus stenosis is an important cause of many reoperations in these patients later in life. Reconstructive strategies that use viable, autologous tissue with growth potential are thus paramount.

Autologous pedicled pericardium is convenient for use in intrapericardial vascular reconstruction of systemic venous, pulmonary venous and pulmonary arterial/right ventricular outflow tract structures. Pedicled pericardium has the theoretical advantage of being vital as it has an intact vascular supply. Thus it also maintains growth potential, as it naturally grows with age to envelop the enlarging heart up to adulthood.

There is a long history of pedicled pericardium use in congenital cardiac surgery reconstructions pioneered by Ledek, Senning, Hvass, and Guyton, and many of these seminal reports were first published decades ago in this Journal. ${ }^{1-4}$ Follow-up in small case series of pedicled pericardium for pulmonary artery and right ventricular outflow tract reconstruction have unequivocally indicated growth. 5,6 Actual histologic studies of pedicled pericardial tubes and patches have been scarce, however, perhaps because of a low reintervention rate. A study by Adachi and

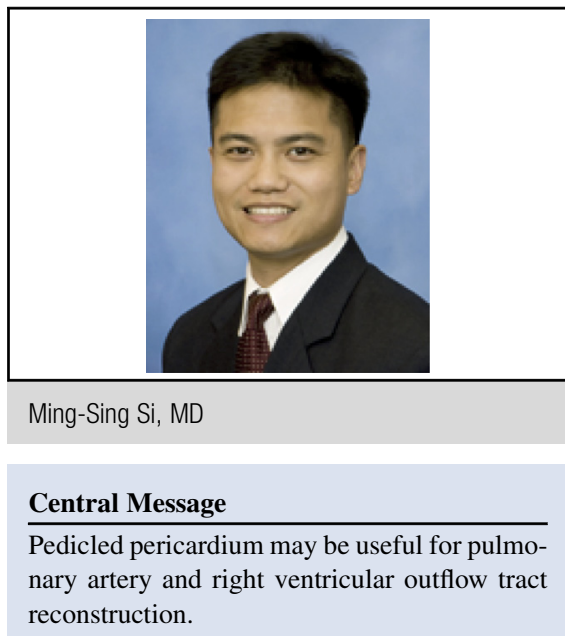

See Article page e11.

associates $^{7}$ demonstrated that pedicled pericardium used as a tube graft in a primary Fontan procedure was pliable, noncalcified and demonstrated microvascularization and an endothelial lining 9 years later.

In this issue of the Journal, Masaki and colleagues ${ }^{8}$ have reported long term follow-up of a pedicled pericardial reconstruction of pulmonary artery and right ventricular outflow tract initially performed as part of a repair of pulmonary atresia with ventricular septal defect in a single patient at 1 year of age. The investigators were able to obtain samples of the pedicled pericardial reconstruction for histologic examination during reoperation for tricuspid and pulmonary valve replacement 16 years later. They found on angiography that the reconstructed right ventricular outflow tract and main pulmonary artery had grown appropriately. During reoperation, the reconstruction was noted to be pliable and without calcification. Histologic and immunohistochemical investigation of explanted pedicled pericardial tissue used in the reconstruction revealed the absence of fibrosis and calcification, the presence of smooth muscle and elastic fiber layers, and a microvascular network. There was no endothelial cell lining detected (although in the setting of a bulk flow conduit, this is probably not a significant demerit). On the basis of these findings, Masaki and colleagues ${ }^{8}$ postulated that the pedicled pericardium acquired a "vascular-like" morphology.

This report is highlighted here because it is further proof, albeit in a single case, of the utility of pedicled pericardium in the reconstruction of the right ventricular 
outflow tract and main pulmonary artery. Currently, the use of allograft and xenogenic material and free (nonpedicled) autologous pericardium in right ventricular outflow tract reconstruction has certainly surpassed that of pedicled pericardium in the United States, probably because of their convenience; however, these materials do not result in a living repair that can grow and regenerate with the patient.

Pedicled pericardium may certainly have limitations. Cases where such an approach results in failure are not likely to be reported. Furthermore, sometimes repair of the right ventricular outflow tract and pulmonary artery occurs in the setting of reoperation, and the ample pericardium needed to perform pedicled reconstruction is no longer available. Also, there is a risk of aneurysmal dilation, although that appears to be only reported to occur infrequently in free pericardial patches. ${ }^{9}$ Nonetheless, the use of pedicled pericardium should be evaluated rigorously in a larger cohort of closely followed patients to determine more precisely its long-term function and durability.

\section{References}

1. Hvass U, Khoury W, Girardet JP, Langlois J. Reconstruction of pulmonary artery branches with pedicled flaps from the autologous pericardium [in French]. Presse Med. 1987;16:441-3.

2. Lepley D Jr, Hausmann PF, Weisel W. The fate of pericardial pedicle grafts used in a fixed position in various chambers of the dog heart. J Thorac Surg. 1959;37: 711-9.

3. Senning A. Correction of the transposition of the great arteries. Ann Surg. 1975; 182:287-92.

4. Tonkin IL, Allen RG, Casini M, Marin-Garcia J, Anthony CL, Bell ED, et al. Modified Shumacker repair of transposition of the great arteries. Surgical and angiocardiographic considerations. J Thorac Cardiovasc Surg. 1983;85:306-12.

5. Khoury W, Lang-Lazdunski L, Vernant F, Thibert M, Leca F. Pedicled pericardium for repair of right ventricular outflow tract and pulmonary arterial stenoses in tetralogy of Fallot: a six-year experience. J Thorac Cardiovasc Surg. 1996;112: 424-32.

6. Ulrik H. Pedicled pericardial flaps. J Thorac Cardiovasc Surg. 1997;113:958.

7. Adachi I, Ishibashi-Ueda H, Yagihara T, Kagisaki K, Hagino I, Ishizaka T, et al. Immunohistologic examination of pedicled autologous pericardium 9 years after implantation for an extracardiac conduit in Fontan pathway: comparison with in situ pericardium and pulmonary arterial tissue from the same patient. J Thorac Cardiovasc Surg. 2007;133:1101-3.

8. Masaki N, Adachi O, Kawamoto S, Saiki Y. Implanted pedicled autologous pericardium mimics vasculature tissue: report of a case. J Thorac Cardiovasc Surg. 2017:153:e11-3.

9. Seybold-Epting W, Chiariello L, Hallman GL, Cooley DA. Aneurysm of pericardial right ventricular outflow tract patches. Ann Thorac Surg. 1977;24: 237-40. 